\title{
16. The phylogenetic species concept and its role in Southeast Asian mammal conservation
}

\author{
Erik Meijaard and Benjamin Rawson
}

\section{Introduction}

Taxonomy may appear a somewhat old-fashioned or even outdated science, but recent heated debate has blown some significant dust off the subject. There is an ongoing dispute between propenents of the Biological Species Concept (BSC) (Zachos, 2013; Zachos et al., 2013) and the Phylogenetic Species Concept (PSC) (Gippoliti and Groves, 2013; Groves, 2013). More precisely the disagreement centres on the perceived implications of the use of either concept for species conservation. Users of the PSC have been accused of causing irresponsible taxonomic inflation and with that dilution of the conservation efforts allocated to each species (Zachos, 2013). The defence of PSC proponents has been that, without the use of the PSC, taxa of potentially significant conservation importance would be overlooked. Such taxa would be ranked as subspecies, and the assumption is that few people or organisations allocate efforts and funding to their conservation. In return, the counterargument has been that subspecies are rarely phylogenetically distinct and do therefore not warrant major conservation efforts (Zink, 2004). The real debate thus appears to be about the best method to allocate an appropriate taxonomic rank to taxa that is in line with their evolutionary distinctness and thus the need to prevent their extinction.

The BSC dates back to the 1930s and remains the most commonly used species concept today. The concept depends on the inference that species are those entities which do not interbreed. When two taxa occur sympatrically (i.e. their ranges overlap) and do not interbreed, the BSC is straightforward to apply. Things get complicated, however, when species occur allopatrically (i.e. no range overlap), because opportunities for interbreeding do not then naturally occur. In fact, many phylogenetic studies indicate a high frequency of gene flow between distinct species, even sympatric ones, with hybridisation often leading to speciation (Bell and Travis, 2005; Mallet, 2007).

As opposed to the BSC, 'the PSC depends on evidence, not on inference' (Groves, 2013: 7). Under the PSC, species are considered to be populations differing by at 
least one taxonomic character from all others, and within each of which there is 'a parental pattern of ancestry and descent' (Cracraft, 1989; Isaac et al., 2004). An absence of interbreeding is not required under the PSC.

Because of its use of evidence (e.g. measurable differences in a sample) rather than inference (e.g. an assumption that two taxa are unlikely to interbreed and produce fertile offspring), the PSC is more likely to lead to taxonomic instability. Two taxa can initially be separated when only a small sample is available, possibly missing some of the variation in the populations of the two taxa (e.g. by not fully sampling a cline). Once more material becomes available, broader variation within either taxon may result in overlap and the conclusion that, after all, the two taxa are not separated as species. Such taxonomic instability concerns conservation organisations that want to be sure that investments in a particular taxon will not be undermined by changes in a species taxonomy.

Taxonomic inflation, or the elevation of many existing subspecies to species level (cf. Isaac et al., 2004), is considered another unwanted side-effect of the use of the PSC (Zachos et al., 2013). With many subspecies being raised to species level, and concommitant shrinking of species' ranges, the list of species of conservation concern would rapidly grow through the use of PSC. It has been argued however that such taxonomic inflation is needed because it was preceeded by irresponsible taxonomic deflation. In the words of BrandonJones and colleagues, 'an increase in recognized species is a desirable reversal of the regrettable trend from about 1920 to 1980, when specific recognition was excessively restrained, with correspondingly reckless subspecific recognition' (Brandon-Jones et al., 2004: 98). A transition from the dominant paradigm of the BSC to the PSC is therefore likely to lead to an increased number of recognised species, an increase of relative threat level at the species level and possibly a reduction in the available conservation resources devoted to each.

We here assess how the application of the PSC has influenced large mammal conservation in Southeast Asia. We look specifically at two groups, the Southeast Asian wild pigs (Suidae) and gibbons (Hylobatidae), because we are most familiar with their conservation through our work as, respectively Chair of the IUCN SSC Wild Pig Specialist Group and Vice-chair of the Section on Small Apes (SSA) of the IUCN SSC Primate Specialist Group. We try to answer three questions: (1) Has conservation attention increased for a taxon since it received full species status? (2) If so, would this increase in conservation attention likely have happened if the species would have remained a subspecies? (3) Has the increase in the recognised number of species in these families led to a detrimental dilution in funding available for all of them. 


\section{Southeast Asian pig taxonomy and conservation}

\section{A history of taxonomic change in Southeast Asian pigs}

Southeast Asia has long been recognised as the center of diversity of wild pig species (Meijaard et al., 2011). At present, 18 extant species of pig are recognised in the family Suidae, the majority of which occur in Southeast Asia. There are two genera in the region, Sus and Babyrousa. Taxonomic revision of the Suidae is ongoing, especially in the Philippines and Indonesia where several taxa are waiting to be described. Even without additional species this is a speciesrich family, reflecting the evolutionary success, ecological versatility, and, considering their endemic presence on a great number of islands, the extensive dispersal ability of pigs.

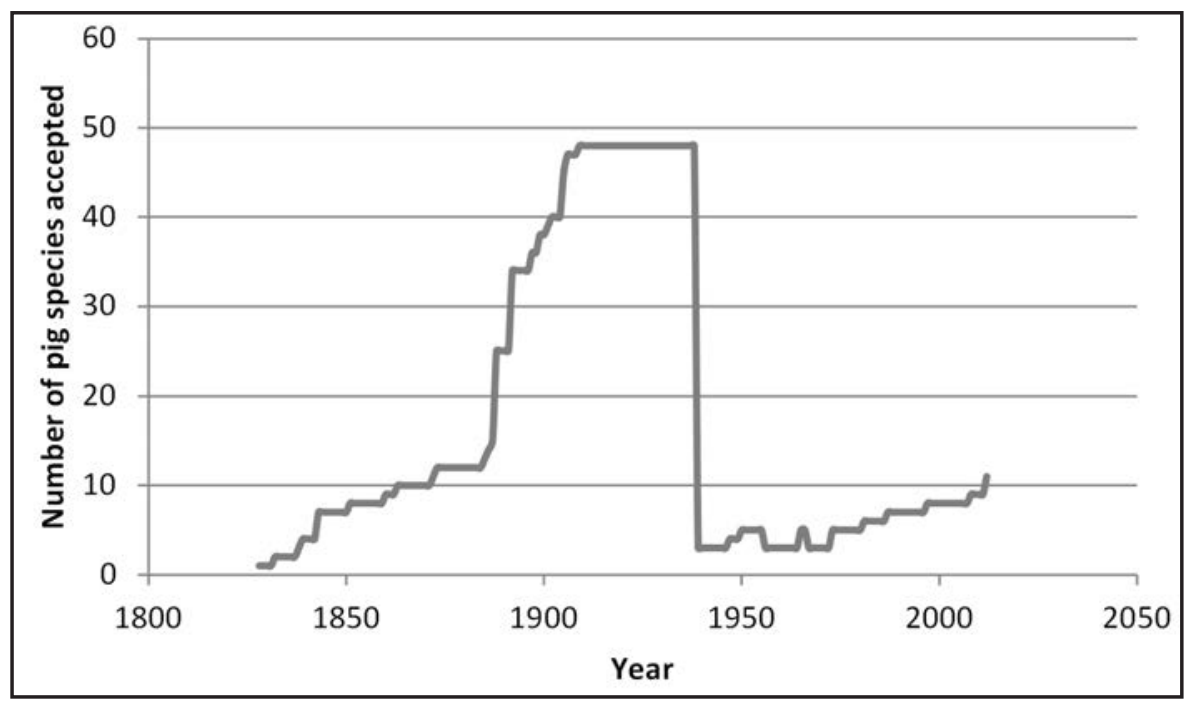

\section{Figure 16.1: Change over time of the number of Southeast Asian pig species described and generally recognised.}

Source: Figure created by authors using authors' own data and data provided in published accounts of species numbers.

The number of Southeast Asian Suidae species has fluctuated greatly over time. In 1758, Linneaus described the first species, Sus scrofa, which ranges over much of the Eurasian landmass, as well as parts of insular Southeast Asia (Meijaard et al., 2011). Following this, there were 80 years of taxonomic stagnation until Sus barbatus, the bearded pig of Sumatra, Borneo and Peninsular Malaysia was described. A general interest in natural history, and specific curiosity about the 
fauna of newly explored parts of Southeast Asia resulted in additional collection of specimens and description of new species (Figure 1). From 1888 onwards, a rapid increase in the number of species was primarily caused by Pierre Marie Heude, a French Jesuit missionary and zoologist based in China. Within the space of a few years, he described some 32 pig species (Heude, 1888, 1892), and by 1909, 48 species of pig had been described in Southeast Asia.

New thinking about what constitues a species, much influenced by evolutionary biologists such as Ernst Walter Mayr, led to major taxonomic lumping of species around the 1940s. The number of pig species in Southeast Asia was reduced to three, and then hovered around the four or five species until the 1980s. A subsequent revision of these taxa by Groves (1981), based on a morphological, ecological and karyological review, reinstated several of the species that had been lumped in the 1940s. This resulted in the following species: Sus scrofa, S. barbatus, $S$. verrucosus, and $S$. celebensis. In addition to these there is the babirusa (Babyrousa babirussa) which Groves did not consider in his 1981 review.

Further application of the phylogenetic species concept led to the recognition of additional species of pig, which in 1993 were officially accepted by the IUCN SSC Pigs, Peccaries and Hippos Specialist Group (Oliver, 1993). In addition to the species above, Sus cebifrons and S. philippensis from the Philippines were now recognised as distinct. The process did not stop there and, in 1997, the Indochinese species S. bucculentus was resurrected (Groves et al., 1997), followed by the separation of the babirusa into three distinct species (Meijaard and Groves, 2002), the description of $S$. oliveri from Mindoro in the Philippines (Groves, 2001 b), and the separation of $S$. ahoenobarbus from Palawan in the Philippines from S. barbatus (Groves, 2001b; Lucchini et al., 2005). These processes have now resulted in 12 suid species in Southeast Asia being recognised by the IUCN.

We note that subsequent work indicates further taxonomic changes, with Sus bucculentus being subsumed into S. scrofa, but S. scrofa itself being split into several distinct species (Groves and Grubb, 2011; Meijaard and Groves, 2013). Sus blouchi from Bawean Island appears to be distinct enough to be allocated to full species level (Groves and Grubb, 2011). Also, an unpublished manuscript found that the pigs from the Sulu Islands in the Philippines were not Sus barbatus, as had been assumed, but a distinct taxon, and in addition, morphological and genetic variation within Sus scrofa indicates consistent differences between, what are presently different subspecies. Finally, recent morphological and genetic studies have indicated that the genus Babyrousa consists of six distinct species rather than the three that are presently recognised (A. MacDonald, pers. comm). These revisions will ultimately result in 15 to 20 recognised species of Suidae in Southeast Asia. 


\section{The impact of taxonomic change on pig conservation}

It is obvious that suid taxonomy is a field in flux. The more we learn about the variation within and between pig taxa and the more we understand the general drivers of such variation, the more likely it has become that taxonomies are revised. Conservation practitioners and scientists generally do not like such taxonomic instability. It interferes with long term conservation planning for species survival and the development of captive breeding and zoo programs. As argued by the opponents of the PSC, the splitting of species leads to a dilution of conservation effort (Zachos et al., 2013). Is this really true however?

The Southeast Asian pig taxa of most conservation concern are the Critically Endangered Visayan warty pig, S. cebifrons, and the Endangered Javan warty pig, S. verrucosus, Mindoro warty pig, S. oliveri, and Togean Babirusa, Babyrousa togeanensis. Three of these (S. cebifrons, S. oliveri and B. togeanensis) were relative recently described using the phylogenetic species concept.

In 1993, the IUCN SSC Pigs, Peccaries and Hippos Specialist Group and other supporting partner agencies (including the Zoological Society of San Diego and, subsequently, the Rotterdam Zoo) devised and initiated a 'Visayan Warty Pig Conservation Programme' with the Philippine Government (Meijaard et al., 2011). Prior to its recognition as a full species, captive populations of Philippine pigs were maintained as single individuals or small groups of animals of mixed origin, and no attempts had been made at captive breeding (Oliver et al., 1993). Since then, two captive breeding and rescue centres for S. cebifrons have been established on Negros Island, and by 2011 at least 87 animals were kept in European zoos alone (Glatston, 2011). The successful breeding programs now require the identification of a safe release site, and this process is ongoing. The species remains highly threatened, but the immediate extinction risk seems to have been averted.

One could argue that the same kind of conservation action could have been undertaken if $S$. cebifrons would have remained a subspecies of $S$. barbatus, where it was originally placed (Groves, 1981). The IUCN presently lists 401 mammal subspecies as threatened, most of which are primates, so it is possible to focus global and local conservation authorities on taxa at the subspecies level. It is doubtful, however, that the Philippine authorities would have been as supportive for the conservation of a subspecies of $S$. barbatus, which also occurs in Indonesia and Malaysia. An interesting comparison for this exists in the Sulu Islands, where there was a locally popular appeal to the Philippine Government to take all due steps to 'eradicate' wild pigs. The government was initially supportive because it treated these populations, which they assumed to be $S$. barbatus, as non-native to the Philippines. Only when studies indicated that the Sulu pig might be an endemic new species to these islands (K Rose 
and P Grubb, unpublished manuscript) were the eradication plans cancelled. The above strongly suggest that recognition of $S$. cebifrons as a full species has played a vital role in preventing its extinction. Another species that appears to have benefited from their recognition as full species is $S$. philippensis, which is now treated as distinct in at least some zoos (e.g. the Amsterdam Zoo).

The two other Endangered species that were only recently elevated to species level appear to have benefited less from this taxonomic change. There are no specific in situ or ex situ programs yet for S. oliveri and B. togeanensis. In fact, the Indonesian Government is presently developing a babirusa action plan, which has retained the original taxonomy that combines the three IUCN-recognised species of babirusa into one. Finally, S. verrucosus blouchi, the Javan warty pig of Bawean Island may be one of the most endangered pig taxa. In anticipation of the taxon being elevated to full species, S. blouchi, as proposed by Groves and Grubb (2011), a survey is presently ongoing to ascertain the status of the taxon. Such conservation activitities had been planned for a long time, and had partly been implemented (Nijman, 2003; Semiadi and Meijaard, 2004), but the recognition that this could be a distinct species has generated renewed efforts to ensure that it will not go extinct.

\section{Gibbon taxonomy and conservation}

\section{A history of taxonomic change in gibbons}

The Hylobatidae have experienced not only a significant increase in the number of species, but an increase in the number of genera over time. Most early authors recognised only one genus in the Hylobatidae, that of Hylobates, with the occassional addition of Symphalangus (e.g. Elliot, 1913; Schultz, 1933). Groves $(1968,1972)$ tentatively recognised three sub-genera, those of Hylobates (which also included the hoolock gibbons), Nomascus and Symphalangus. This approach was later supported to a large degree by genetic evidence (Hall et al., 1998; Hayashi et al., 1995; Roos and Geissmann, 2001; Takacs et al., 2005). Groves (2001a) added a fourth subgenus, Bunopithecus, for the hoolock gibbons, but later changed its name to Hoolock (Mootnick and Groves, 2005). These four subgenera were subsequently raised to generic status (Brandon-Jones et al., 2004; Geissmann, 2002), and are now commonly recognised (e.g. Meyer et al., 2012; Takacs et al., 2005). Groves, therefore played a fundamental role in development of the currently understood systematics of the Hylobatidae at the generic level. 


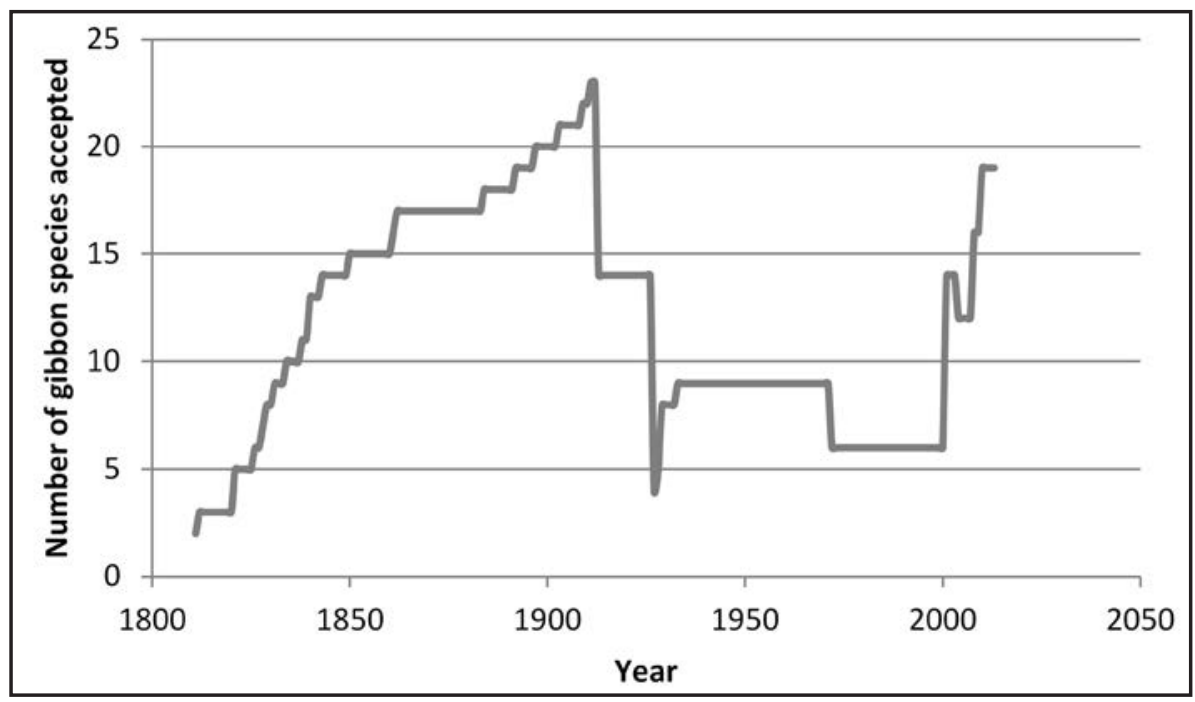

Figure 16.2: Change over time of the number of gibbon species described and generally recognised.

Source: Figure created by authors using authors' own data and data provided in published accounts of species numbers.

Similar to the rapid increase in Suidae species described above, the Hylobatidae experienced a rapid increase in the number of described species between the mid-nineteenth and early twentieth century. From a maximum of 23 species, this was reduced to four by Pocock (1927), revised to seven by Kloss (1929), and subsequently to nine by Schultz (1933). Groves also played a significant role in the species-level taxonomy for the Hylobatidae. His taxonomic review in 1972 reduced the number of species to six (Groves, 1972). In 1967, Groves had already described a second sub-species of the hoolock gibbon, Hylobates hoolock leuconedys from east of the Chindwin River, but it was not until much later that this taxon was elevated to generic and specific status as Hoolock leuconedys (Mootnick and Groves, 2005). Further taxonomic reviews by Brandon-Jones and others (2004), Mootnick and Fan (2011) and Thinh and others (2010) revealed the distinctness of additional gibbon species, and in the latest review of the gibbons, 19 species of Hylobatidae are recognised (Mittermeier et al., 2013). Sixteen of these are listed on the IUCN Red List and three remain unassessed. Of these 16, four are Critically Endangered, 11 Endangered, and one Vulnerable (IUCN, 2013). 
Taxonomic Tapestries

\section{The impact of taxonomic change on gibbon conservation}

While some taxa such as Hylobates klossii, Symphalangus syndactylus and $H$. moloch have undergone no recent taxonomic rearrangements, and as such have not been significantly subjected to changes in priority setting, other taxa have. For example, the raising of the eastern hoolock (Hoolock leuconedys) to specific status (Mootnick and Groves, 2005) and discovery of a population in Assam, India reportedly changed conservation priorities in this area, previously believed to only contain Hoolock hoolock (J. Das, pers. comm.). The discovery of Nomascus annamensis between the distributions of N. gabriellae and N. siki in 2010 (Thinh et al., 2010) has opened up additional funding opportunities for gibbons located in its area of occurrence (Rawson, pers. obs.).

The Cao Vit gibbon (Nomascus nasutus) was until 2004 considered a subspecies of N. concolor (Brandon-Jones et al., 2004; Groves, 2001a), and as such the single remaining population of approximately 129 individuals on the Sino-Vietnamese border would have been considered a low priority compared to healthier populations in China, specifically Wuliangshan and Ailaoshan. However, it has now become the second most threatened gibbon taxon after the Hainan gibbon (Nomascus hainanus) and considerable conservation funding flows to this population as a result.

To further educate discussion about how taxonomic change has impacted gibbon conservation we sent out a survey to all members $(n=53)$ of the IUCN Species Survival Commission, Primate Specialist Group, Section on Small Apes and received 24 responses. All 19 Hylobatidae taxa recognised in Handbook of the mammals of the world, Volume 3: Primates (Mittermeier et al., 2013) were listed by at least one respondent as a taxon they had worked on. The average time that respondents had been engaged in gibbon conservation was approximately 13 years, providing a sufficiently long period of time and sufficient taxonomic coverage to expect to detect changes in relation to taxonomic inflation.

When asked whether taxonomic inflation had led to the recognition of too many gibbon species, responces were split with 33.3\% answering yes, 29.2\% answering no and $37.5 \%$ expressing no firm opinion. However, when asked whether changes in taxonomy had ever changed their conservation priorities, such as focusing on a newly elevated subspecies, the vast majority said it had not ( $\mathrm{n}=24,91.7 \%$ answered 'no' while only $8.3 \%$ answered 'yes'). The most common rationale cited for not changing priorities was that at the population level, changes in taxonomy do not change conservation interventions required. In other words, the units of conservation commonly of interest to gibbon conservationists are smaller than that of species and occur at the site or population level. Several respondents noted that as gibbons are so rare 
and under high threat, taxonomic assessments are not significant drivers for conservation interventions and instead they focus on population conservation irrespective of taxonomic affiliation.

Responses to a question concerning whether funding for gibbons had increased, decreased or remained static were split, with $8.3 \%$ reporting a decrease, $16.7 \%$ an increase, $50 \%$ no change and $25 \%$ did not know. In fact, changes in funding for gibbon conservation in relation to taxonomic inflation are likely confounded by the increased funding being fed into gibbon conservation in general. Important funding mechanisms such as the USFWS Great Ape Conservation Grant (GACF) (which also includes the Hylobatidae in calls for proposals) and the more recent significant investment by the Arcus Foundation have come online during the most recent expansion in the number of gibbon taxa. Between 2007 and 2011, for example, USFWS GACF provided \$25,541,000 for ape conservation, and although the amount specifically allocated for gibbon conservation is unknown, this doubtless represents a significant investment which was not available before the grants inception in 2001. Likewise, the Arcus Foundation has invested at least $\$ 3,500,000$ in gibbon specific conservation since it began funding gibbons in 2007 (H. Rainer, pers. comm.).

From a captive management perspective, there are implications of taxonomic inflation. One significant issue is that splitting of taxa may result in captive populations of previously taxonomically homogenous individuals being assessed as hybrids. For example, raising Nomascus siki and N. leucogenys to species level has resulted in a large number of hybrid animals being held in zoos as founder captive populations did not distinguish these taxa at species level (Petersen and Melfi, pers. comm.). The value of hybrid gibbons from a conservation and reintroduction standpoint is much lower than non-hybrids. A further implication of taxonomic inflation in gibbons is that the increased number of taxa means that zoos, because of limited space, are unable to hold significant collections of all species (either independently or collectively). This is resulting in a triage approach limiting which taxa of gibbons are held in regional collections. Quite simply, as the number of taxa increase, the percentage of taxa which can be incorporated into breeding programs decreases. Moreover, the number of wrongly identified gibbons is likely to have increased.

\section{Discussion}

We have reviewed the impact of the use of the phylogenetic species concept on the conservation of two groups of Southeast Asian mammals, pigs and gibbons. We find that at least for some taxa there appears to have been a clear benefit of being considered full species, in terms of commitment from national governments 
to ensure their survival, generate funding for their in situ protection, develop breeding programs, and raise their global profile. This seems obvious for the gibbons for which major funding from the Arcus Foundation and United States Fish and Wildlife Service has been allocated for their protection. This funding has increased with the increasing threat level to the species, which in turn relates to taxonomy. As an example, under the more conservative 1972 taxonomy which largely follows a BSC, the remaining 129 Nomascus nasutus gibbons would be unlikely to get the same level of attention as they get now. Similarly, for pigs, renewed funding support was sought for Bawean pig (Sus (v.) blouchi) when it became clear that this was likely an endemic species of the island. Similarly, specific programs for Visayan warty pig (Sus cebifrons) were only developed once it became clear that the species was distinct. In contrast, we did not encounter examples in which funding per species or attention to their conservation had decreased following their elevation to species level, although, we recognise that our sample of pigs and gibbons is only a small part of the total number of globally threatened taxa, and possibly not representative.

We cannot fully assess the counterfactual, that whether the same kind of conservation support could have been generated if these taxa had remained as subspecies. Total funding for biodiversity conservation is likely to increase over time, with growing global concerns about species extinction and unsustainable use of natural resources (Leiserowitz et al., 2006; Sachs et al., 2009), and a general recognition that more conservation funding is needed to meet biodiversity targets (McCarthy et al., 2012). These processes could take place independent of whichever taxonomic principles or species definitions are followed. It is unclear whether there is a fixed amount of conservation funding available for all species and that adding species would dilute the funding available for each species. Or alternatively, funding levels could actually increase with the number of threatened taxa that require improved conservation management, in which case an increasing number of species would translate into an increasing amount of focus and funding. At least based on our analysis, the latter rather than the former seems the case, and dilution of conservation funding because of taxonomic inflation does not seem to be a major concern.

Another issue of importance, which was revealed through the feedback from the Section on Small Apes of the Primate Specialist Group, is that most people have been working long-term at the site level and do not really feel that taxonomy has much to do with how they approach conservation. They approach conservation from a broader ecological and management point of view and focus efforts on habitat protection. Changing the status of a subspecies to a species is not perceived to be of much consequence to their work. Again, this would indicate that there is limited harm in applying the more stringent PSG, even if this leads to an increase in the number of species. With an increase in the number of 
species, individual populations and sites generally become more important to that taxon, rather than less important. For example, the recent description of Nomascus annamensis (Thinh et al., 2010) significantly reduced the understood range of both $N$. siki and $N$. gabriellae which it falls between, making at least $N$. siki a much higher conservation priority due to a range reduction with fewer sites containing potentially viable populations.

From a conservation standpoint, the discussion about conservation impacts of the use of a BSC rather than PSC ultimately leads to the question of what is the unit of conservation. The IUCN recognises subspecies as a valid unit of conservation, and indeed has assessed 1,838 subspecies of Animalia and Plantae (no Fungi or Protista have been assessed at the subspecies level) compared with 70,289 taxa assessed at the species level (IUCN, 2013). Thus about $2.6 \%$ of assessed threatened taxa are subspecies. If the analysis is restricted to South and Southeast Asia, there are 302 subspecies assessed by the IUCN, compared with 16,855 species (i.e. $1.8 \%$ of the total). These figures indicate that, although conservation status assessments at the subspecies level exist, such assessments are relatively rare. IUCN status assessments are an important driver of conservation action (Hoffmann et al., 2010; Rodrigues et al., 2006), and considering the relative low uptake of subspecies-level assessments, a precautionary approach would be to err on the side of inflated rather than under-estimated taxonomic diversity.

Finally, there may be good reasons for not underestimating taxonomic diversity. A recent global analysis of avian subspecies showed that $36 \%$ of avian subspecies are, in fact, phylogenetically distinct (Phillimore and Owens, 2006). Interestingly, the authors found significant differences in the proportion of subspecies that are phylogenetically distinct, with Nearctic/Palearctic subspecies showing significantly reduced levels of differentiation. Additionally, the authors found differences between island and continental subspecies, with continental subspecies significantly less likely to be genetically distinct. These results indicate that the overall level of congruence between taxonomic subspecies and molecular phylogenetic data is greater than previously thought. Phillimore and Owens suggest that the widespread impression that avian subspecies are not real arises from a predominance of studies focusing on continental subspecies in North America and Eurasia, regions which show unusually low levels of genetic differentiation (Phillimore and Owens, 2006). These findings are reflected by our own phylogenetic and taxonomic studies in Southeast Asia, which indicate ancient patterns of species diversification in a region that has maintained relative climatic stability compared with the higher latitudinal areas that were significantly affected by glacial cycles (de Bruyn et al., 2014; Meijaard, 2004). In addition, the main islands in the Malay Archipelago (Wallace, 1869) and high geological activity and concommitant topographical changes in the region 
(Meijaard and Groves, 2006) have resulted in much higher speciation rates than in continental North America and Eurasia. Taking into account that taxonomic research in Southeast Asia is practiced by few scientists (Meijaard and Sheil, 2012), and that many taxonomic studies and updates therefore remain pending, we expect there to be significant undiscovered or overlooked taxonomic diversity in Southeast Asia.

In conclusion, our study suggests that the use of a phylogenetic species concept has been beneficial to the conservation of species in the Southeast Asian region. So-called taxonomic inflation in Southeast Asia is needed to ensure that we identify as many evolutionary distinct species of conservation concern as possible. The efforts by Groves and colleagues to recognise distinct taxa using the PSC therefore appears to be warranted in Southeast Asia, where much taxonomic variation remains hidden and conservation needs are higher than anywhere else (di Marco et al., 2014).

\section{Acknowledgements}

Ben Rawson thanks the membership of the IUCN SSC Primate Specialist Group Section on Small Apes membership for their input into discussions on taxonomic inflation and impacts on conservation priorities. We thank Colin Groves for his wonderful mentorship, commitment to good science and conservation, and unfailing willingness to help whenever he can.

\section{References}

Bell MA, Travis MP. 2005. Hybridization, transgressive segregation, genetic covariation, and adaptive radiation. Trends Ecol Evol 20(7):358-361.

Brandon-Jones D, Eudey AA, Geissmann T, Groves CP, Melnick DJ, Morales J, Shekelle M, Stewart T. 2004. Asian primate classification. Int J Primatol 25(1):97-164.

Cracraft J. 1989. Speciation and its ontology: The empirical consequences of alternative species concepts for understanding patterns and processes of differentiation. In: Otte D, and Endler JA, editors. Speciation and its consequences. Sunderland, MA: Sinauer Associates. pp. 28-59.

de Bruyn M, Stelbrink B, Morley RJ, Hall R, Carvalho GR, Cannon CH, van den Bergh G, Meijaard E, Boitani L, Maiorano L, Shoup R, von Rintelen T. 2014. Borneo and Indochina are major evolutionary hotspots for Southeast Asian biodiversity. Systematic Biology 63:879-901. 
Di Marco M, Boitani L, Mallon D, Iacucci A, Visconti P, Meijaard E, Schipper J, Hoffmann M, Rondinini C. 2014. Lessons from the past: A retrospective evaluation of the global decline of carnivores and ungulates. Conserv Biol 28(4):1109-1118.

Elliot DG. 1913. A review of the primates. American Museum of Natural History Monograph series 1. New York: American Museum of Natural History. pp. $1-317$.

Geissmann T. 2002. Taxonomy and evolution of gibbons. Evol Anth 11(S1):2831.

Gippoliti S, and Groves CP. 2013. 'Taxonomic inflation' in the historical context of mammalogy and conservation. Hystrix 23(2): 8-11.

Glatston A. 2011. Regional Visayan warty pig studbook. Sus cebifrons negrinus. Rotterdam, the Netherlands: Rotterdam Zoo.

Groves CP. 1968. The classification of the gibbons (Primates, Pongidae). $Z$ für Säugetierkunde 33:239-246.

Groves CP. 1972. Systematics and phylogeny of gibbons. In: Rumbaugh DM, editor. Gibbon and Siamang, Vol. 1. Basel: Karger. pp. 1-89.

Groves CP. 1981. Ancestors for the pigs. Canberra: Australian National University Press. p. 96.

Groves CP. 2001a. Primate taxonomy. Washington DC: Smithsonian Institution Press. p. 350.

Groves CP. 2001b. Taxonomy of wild pigs of Southeast Asia. Asian Wild Pig News 1(1):2-3.

Groves CP. 2013. The nature of species: A rejoinder to Zachos et al. Mammal Biol - Z für Säugetierkunde 78(1):7-9.

Groves CP, Grubb P. 2011. Ungulate taxonomy. Baltimore, Maryland: Johns Hopkins University Press.

Groves CP, Schaller GB, Amato G, Khounboline K. 1997. Rediscovery of the wild Sus bucculentus. Nature 386(27 March 1997):335.

Hall LM, Jones DS, Wood BA. 1998. Evolution of the gibbon subgenera inferred from Cytochrome b DNA sequence data. Mol Phyl Evol 10(3):281-286.

Hayashi S, Hayasaka K, Takenaka O, Horai S. 1995. Molecular phylogeny of gibbons inferred from mitochondrial DNA sequences: Preliminary report. $J$ Mol Evol 41:359-365. 
Taxonomic Tapestries

Heude PM. 1888. Étude sur les suilliens. Mémoires concernant l'histoire naturelle de l'Empire chinois 2:85-111.

Heude PM. 1892. Étude sur les suilliens, chapitre 4, etc. Mémoires concernant l'histoire naturelle de l'Empire chinois 4(3/4):113-211.

Hoffmann M, Hilton-Taylor C, Angulo A, Bohm M, Brooks TM, Butchart SHM, Carpenter KE, Chanson J, Collen B, Cox NA et al. 2010. The impact of conservation on the status of the world's vertebrates. Science 330(6010):15031509 .

Isaac NJB, Mallet J, Macdonald AA. 2004. Taxonomic inflation: Its influence on macroecology and conservation. Trends Ecol Evol 19(9):464-469.

International Union for Conservation of Nature (IUCN). 2013. IUCN Red List of threatened species. Version 2012.2. www.iucnredlist.org. accessed 10 May 2013.

Kloss CB. 1929. Some remarks on the Gibbons, with the description of a new sub-species. Proc Zool Soc Lond 99(1):113-127.

Leiserowitz AA, Kates RW, and Parris TM. 2006. Sustainability values, attitudes, and behaviors: A review of multinational and global trends. Annu Rev Environ Resour 31: 413-444.

Lucchini V, Meijaard E, Diong CH, Groves CP, Randi E. 2005. New phylogenetic perspectives among species of Southeast Asian wild pig (Sus sp.) based on mtDNA sequences and morphometric data. J Zool 266(1):25-35.

McCarthy DP, Donald PF, Scharlemann JPW, Buchanan GM, Balmford A, Green JMH, Bennun LA, Burgess ND, Fishpool LDC, Garnett ST et al. 2012. Financial costs of meeting global biodiversity conservation targets: Current spending and unmet needs. Science 338(6109):946-949.

Mallet J. 2007. Hybrid speciation. Nature 446(7133):279-283.

Mayr E. 1942. Systematics and the origin of species from the viewpoint of a zoologist. New York: Columbia University Press.

Meijaard E. 2004. Solving mammalian riddles. A reconstruction of the Tertiary and Quaternary distribution of mammals and their palaeoenvironments in island Southeast Asia. PhD thesis, Department of Anthropology and Archaeology, The Australian National University.

Meijaard E, d'Huart JP, Oliver WLR. 2011. Family Suidae (Pigs). In: Wilson DE, Mittermeier RA, editors. Handbook of the mammals of the world, Vol. 2 Hoofed mammals. Barcelona, Spain: Lynx Edicions. pp. 248-291. 
Meijaard E, Groves CP. 2002. Upgrading three subspecies of babirusa (Babyrousa sp.) to full species level. Asian Wild Pig News 2(2):33-39.

Meijaard E, Groves CP. 2006. The geography of mammals and rivers in mainland Southeast Asia. In: Lehman S, and Fleagle J, editors. Primate biogeography. New York: Kluwer Academic Publishers. pp. 305-329.

Meijaard E, Groves CP. 2013. New taxonomic proposals for the Sus scrofa group in eastern Asia. Suiform Soundings 12(1):26-30.

Meijaard E, Sheil D. 2012. The dilemma of green business in tropical forests: How to protect what it cannot identify. Conserv Lett 5(5):342-348.

Meyer TJ, McLain AT, Oldenburg JM, Faulk C, Bourgeois MG, Conlin EM, Mootnick AR, de Jong PJ, Roos C, Carbone L et al. 2012. An Alu-based phylogeny of gibbons (Hylobatidae). Mol Phyl Evol 29(11):3441-3450.

Mittermeier RA, Rylands AB, Wilson DE, editors. 2013. Handbook of the Mammals of the World, Vol. 3 Primates. Barcelona, Spain: Lynx Edicions.

Mootnick A, Groves C. 2005. A new generic name for the hoolock gibbon (Hylobatidae). Int J Primatol 26(4):971-976.

Mootnick AR, Fan P-F. 2011. A comparative study of crested gibbons (Nomascus). Am J Primatol 73(2):135-154.

Nijman V. 2003. Notes on the conservation of the Javan Warty Pig Sus verrucosus blouchi on the island of Bawean. Asian Wild Pig News 3(1):15-16.

Oliver WLR. 1993. Pigs, peccaries, and hippos. Status survey and conservation action plan. Gland, Switzerland: IUCN SSC Pigs and Peccaries Specialist group and IUCN SSC Hippos Specialist Group.

Oliver WLR, Cox CR, Groves CP. 1993. The Philippine Warty Pigs (Sus philippensis and S. cebifrons). In: Oliver WLR, editor. Pigs, peccaries, and hippos. Status survey and conservation action plan. Gland, Switzerland: IUCN. pp. 145-155.

Phillimore AB, Owens IPF. 2006. Are subspecies useful in evolutionary and conservation biology? Proc R Soc Lond B Biol Sci 273(1590):1049-1053.

Pocock RI. 1927. The gibbons of the genus Hylobates. J Zool Ser A Proc Zool Soc Lond 97(3):719-741.

Rodrigues ASL, Pilgrim JD, Lamoreux JF, Hoffmann M, Brooks TM. 2006. The value of the IUCN Red List for conservation. Trends Ecol Evol 21(2):71-76.

Roos C, Geissmann T. 2001. Molecular phylogeny of the major Hylobatid divisions. Mol Phyl Evol 19(3):486-494. 
Taxonomic Tapestries

Sachs JD, Baillie JEM, Sutherland WJ, Armsworth PR, Ash N, Beddington J, Blackburn TM, Collen B, Gardiner B, Gaston KJ et al. 2009. Biodiversity conservation and the millennium development goals. Science 325(5947):15021503.

Schultz AH. 1933. Observations on the growth, classification and evolutionary specialization of gibbons and siamangs. Hum Biol 5:212-255, 385-428.

Semiadi G, Meijaard E. 2004. Survey of the Javan warty pig (Sus verrucosus) on Java and Bawean Island, with English summary and detailed survey results in Indonesian. Bogor, Indonesia: Pusat Penelitian Biologi-LIPI and IUCN SSC Pigs, Peccaries and Hippos Specialist Group.

Takacs Z, Morales JC, Geissmann T, Melnick DJ. 2005. A complete specieslevel phylogeny of the Hylobatidae based on mitochondrial ND3-ND4 gene sequences. Mol Phyl Evol 36(3):456-467.

Thinh VN, Mootnick AR, Thanh VN, Nadler T, Roos C. 2010. A new species of crested gibbon, from the central Annamite mountain range. Vietnamese $J$ Primatol 4:1-12.

Wallace AR. 1869. The Malay Archipelago. Oxford: Oxford University Press. p. 625 .

Zachos FE. 2013. Taxonomy: Species splitting puts conservation at risk. Nature 494(7435):35.

Zachos FE, Apollonio M, Bärmann EV, Festa-Bianchet M, Göhlich U, Habel JC, Haring E, Kruckenhauser L, Lovari S, McDevitt AD et al. 2013. Species inflation and taxonomic artefacts: A critical comment on recent trends in mammalian classification. Mammal Biol - Z für Säugetierkunde 78(1):1-6.

Zink RM. 2004. The role of subspecies in obscuring avian biological diversity and misleading conservation policy. Proc R Soc Lond B Biol Sci 271:561-564. 
This text is taken from Taxonomic Tapestries: The Threads of Evolutionary, Behavioural and Conservation Research, edited by Alison M Behie and Marc F Oxenham, published 2015 by ANU Press, The Australian National University, Canberra, Australia. 